\title{
Determination of Volatile Compounds in Foxtail Millet Sake Using Headspace Solid-Phase Microextraction and Gas Chromatography-Mass Spectrometry
}

\author{
Jingke Liu, ${ }^{1,2,3}$ Wei Zhao,, ${ }^{1,2,3}$ Shaohui Li, ${ }^{1,2,3}$ Aixia Zhang, \\ Yuzong Zhang, ${ }^{1,2,3}$ and Songyan Liu ${ }^{4}$ \\ ${ }^{1}$ Institute Millet Crops of Hebei, Academy of Agriculture and Forestry, No. 162, Hengshan Street, Shijiazhuang, \\ Hebei 050035, China \\ ${ }^{2}$ National Millet Improvement Center of China, No. 162, Hengshan Street, Shijiazhuang, Hebei 050035, China \\ ${ }^{3}$ Minor Cereal Crops Research Laboratory of Hebei Province, No. 162, Hengshan Street, Shijiazhuang, Hebei 050035, China \\ ${ }^{4}$ Shijiazhuang Livestock Products Quality Inspection \& Supervision Center, No. 3, Yixi Street, Shijiazhuang, \\ Hebei 050041, China
}

Correspondence should be addressed to Yuzong Zhang; zyz56@163.com

Received 21 May 2015; Revised 30 September 2015; Accepted 1 October 2015

Academic Editor: Javier Hernandez-Borges

Copyright (C) 2015 Jingke Liu et al. This is an open access article distributed under the Creative Commons Attribution License, which permits unrestricted use, distribution, and reproduction in any medium, provided the original work is properly cited.

\begin{abstract}
The volatile compounds in foxtail millet sake were extracted by headspace solid-phase microextraction (HS-SPME) and analyzed using gas chromatography-mass spectroscopy (GC-MS). Different methods of sample preparation were used to optimize this method (SPME fiber types, sample amount, extraction time, extraction temperature, content of $\mathrm{NaCl}$, and rotor speed). For final method of sample preparation, $8 \mathrm{~mL}$ of sake was placed in a $15 \mathrm{~mL}$ headspace vial with addition of $1.5 \mathrm{~g}$ of $\mathrm{NaCl}$; a $50 / 30 \mu \mathrm{m}$ DVB/CAR/PDMS SPME fiber was used for extraction at $50^{\circ} \mathrm{C}$ for $30 \mathrm{~min}$ with $10 \mathrm{rpm}$ continuous stirring. A total of 41 volatile compounds were identified from the sake sample, including 9 esters, 6 alcohols, 4 acids, 4 aldehydes, 9 hydrocarbons, 7 benzene derivatives, and 2 others. The main volatile compounds were ethyl acetate, phenylethyl alcohol, butanedioic acid diethyl ester, and hexadecane. According to their odors active values (OAVs), 10 volatile compounds were established to be odor active compounds and to contribute to the typical foxtail millet sake aroma. Hexanoic acid ethyl ester was the most prominent odor active compound.
\end{abstract}

\section{Introduction}

Foxtail millet (Setaria italica) is an important grain crop grown in arid areas. It has been cultivated extensively in Eurasia for both food and forage. It plays a very important role in the agriculture and food industries of many developing countries because of its capacity to grow under adverse heat and limited rainfall conditions [1]. It has excellent drought tolerance and water-use efficiency, which may be the reason why it is still widely cultivated as a dietary staple in the arid and semiarid regions in the world, particularly in China and India. Foxtail millet is one of the most popular cereal crops cultivated and consumed in China. The total area of foxtail millet cultivation in China is approximately $1,400 \mathrm{~km}^{2}$, and total production is in the range of 3,700-4,500 thousand tons per year [2]. It is used in the production of porridge, cooked millet, and baby cereal. Foxtail millet can also be used in wine production, including distilled spirits, yellow wine, and sake. Among many kinds of wine, foxtail millet sake is deeply loved by consumers because of its unique sensory quality and nutritional value.

Sake is a popular alcoholic beverage, and it is usually made from rice. Among its various attributes, aroma is considered of primary importance in that superior scent increases consumer satisfaction, overall acceptability, and the probability of repeated purchase. The aroma of rice sake is typically described as having "caramel," "burnt," "heavy," and "complicated" characteristics [3]. In the study of sake, esters, acids, sulfur compounds, and carbonyl compounds were reported to contribute to the sake aroma, especially 
TABLE 1: General composition of the foxtail millet sake $(n=3)$.

\begin{tabular}{lcccccc}
\hline $\begin{array}{l}\text { Alcohol } \\
(\% \mathrm{v} / \mathrm{v})\end{array}$ & $\mathrm{pH}$ & $\begin{array}{c}\text { Total acidity } \\
(\mathrm{g} / \mathrm{L} \text { as lactic acid })\end{array}$ & $\begin{array}{c}\text { Total sugar } \\
(\mathrm{g} / \mathrm{L} \text { as glucose })\end{array}$ & $\begin{array}{c}\text { Nonsugar solidity } \\
(\mathrm{g} / \mathrm{L})\end{array}$ & $\begin{array}{c}\text { Amino acid nitrogen } \\
(\mathrm{g} / \mathrm{L})\end{array}$ & $\begin{array}{c}\text { Ash } \\
(\mathrm{g} / \mathrm{L})\end{array}$ \\
\hline $10.87 \pm 0.92$ & $3.53 \pm 0.32$ & $3.02 \pm 0.28$ & $12.86 \pm 0.86$ & $11.76 \pm 1.01$ & $0.23 \pm 0.02$ & $0.88 \pm 0.07$ \\
\hline
\end{tabular}

3-hydroxy-4,5-dimethyl-2(5H)-furanone (sotolon), which was identified as a burnt flavoring compound for sake aroma $[4,5]$. However, most of these studies have focused on rice sake, and the volatile compounds and odor-contributing compounds of foxtail millet sake are still not well defined.

In previous sake reports, several extraction-concentration methods were used for analysis of volatile compounds in wine, such as liquid-liquid extraction $[6,7]$, solid-phase extraction [8], and headspace extraction $[9,10]$. Most of these techniques have several disadvantages, including extensive equipment requirements, a need for significant quantities of expensive and environmentally unfriendly solvents, multiple handling steps that increase the risk of error, and a need to concentrate the target for analysis. Solid-phase microextraction (SPME) has been established as an analyte sampling/enrichment approach for trace compound analysis in various sample matrices. This technique had been applied to the analysis of volatile compounds in alcoholic beverages such as wine $[11,12]$, Chinese liquor $[4,13]$, beer $[14,15]$, and cider [16] because of its ease of use, good reproducibility, and lack of a need for either large samples or solvents of any kind [17-19]. With high repeatability, GC-MS is known as an objective, quick, and accurate technique for evaluating the volatile compounds in alcoholic products. GC-MS is used for quantitative purposes, and a precise quantification is required for determining odor activity value (OAV). OAV calculation depends on measuring both concentration and odor threshold in the same matrix. The contribution of volatiles to the final aroma depends on those odorants with $\mathrm{OAV}>1$. So OAV was widely introduced to choose impact odorants in alcoholic beverage [20].

The objective of this study was to use HS-SPME and GCMS to analyze the volatile compounds in foxtail millet sake and evaluate contributions of specific volatile compounds on the aroma of the overall sample. The results of the study could be important for fostering a better understanding of the volatile compounds in typical foxtail millet sake and could also improve the quality of foxtail millet sake.

\section{Experimental Procedure}

2.1. Foxtail Millet Sake. Foxtail millet sake was obtained directly from a manufacturer (Ruihe Manor Liquor Industry Co., Ltd.). The sake samples were stored in the dark at $4^{\circ} \mathrm{C}$. Alcohol, pH, total acidity, total sugar, nonsugar solids, amino acid nitrogen, and ash (Table 1) analyses were performed in wine according to standard methods [21].

2.2. Chemicals. 3-Octanol (99.0\%), ethyl acetate (99.5\%), hexanoic acid ethyl ester (99.0\%), octanoic acid ethyl ester (99.0\%), benzoic acid ethyl ester (99.5\%), butanedioic acid diethyl ester (99.0\%), pentanedioic acid diethyl ester (99.0\%), decanoic acid ethyl ester (99.5\%), hexadecanoic acid ethyl ester (99.0), 2,3-butanediol (99.0\%), 2nonanol (98.0\%), 2-ethyl-1-hexanol (99.5\%), phenylethyl alcohol (99.0\%), 2-decanol (98.0\%), hexanoic acid (99.5\%), nonanoic acid $(97.0 \%)$, decanoic acid $(98.0 \%)$, benzaldehyde (99.5\%), decanal (96.00\%), dodecanal (95.50\%), dodecane (99.50\%), tridecane $(99.50 \%)$, tetradecane $(99.50 \%)$, pentadecane $(99.50 \%)$, hexadecane $(99.50 \%)$, heptadecane $(99.50 \%)$, octadecane $(99.00 \%)$, eicosane $(99.00 \%)$, styrene $(99.0 \%)$, 1,2,3-trimethylbenzene (99.5\%), naphthalene (99.50\%), 1methylnaphthalene (99.00\%), butyrolactone (97.0\%), and benzothiazole (96.0\%) were purchased from Dr. Ehrenstorfer $\mathrm{GmbH}$ (Augsburg, Germany) and Sigma-Aldrich (St. Louis, MO, USA).

\subsection{Headspace Solid-Phase Microextraction (Headspace-} $S P M E-G C-M S)$. Five kinds of SPME fibers with different coats were purchased from Supelco Inc. (Bellefonte, PA, USA). They were $85 \mu \mathrm{m}$ polyacrylate (PA), $100 \mu \mathrm{m}$ polydimethylsiloxane (PDMS), $65 \mu \mathrm{m}$ PDMS/divinylbenzene (PDMS/DVB), $75 \mu \mathrm{m}$ carboxen/polydimethylsiloxane (CAR/ PDMS), and 50/30 $\mu \mathrm{m}$ DVB/CAR/PDMS. The fibers used were preconditioned before analysis in the injection port of the gas chromatograph according to the manufacturer's instructions.

Sample, $\mathrm{NaCl}$, and a magnetic stir bar were placed in a $15 \mathrm{~mL}$ vial (specific to SPME). Before the SPME fiber was inserted into the vial, the vial was sealed with one Teflon cover and equilibrated for $20 \mathrm{~min}$ in a water bath. After that, the fiber was exposed in the upper space of the sealed vial to extract compounds. Preliminary experiments were carried out to evaluate the HS-SPME process by optimizing the main parameters, that is, fiber types, amount of sample, extraction time, extraction temperature, concentration of $\mathrm{NaCl}$, and rotor speed. After extraction, the fiber was inserted into the injection port of $\mathrm{GC}\left(250^{\circ} \mathrm{C}\right)$ for $5 \mathrm{~min}$ to desorb the analytes. The internal standard 3-octanol solution at $50 \mathrm{mg} / \mathrm{L}$ in absolute ethanol was added in sample under optimal extraction conditions. Extraction of each sample was performed in triplicate. After extraction, n-alkanes (C8-C20,) were injected under the same conditions for calculating RI.

2.4. Gas Chromatography-Mass Spectrometry (GC-MS). The procedure described by Luo et al. [4] and Fan and Qian [13] was used with some modification. GC-MS was performed using an HP 5975B quadrupole mass selective detector (Agilent Technologies, USA). The mass spectral ionization temperature was set to $230^{\circ} \mathrm{C}$. The mass spectrometer was operated in the electron impact ionization mode at a voltage of $70 \mathrm{eV}$. Mass spectra were taken over an $\mathrm{m} / \mathrm{z}$ range of $30-$ 400. The flow rate of the helium carrier gas on the DB-5 
column $(30 \mathrm{~m} \times 0.25 \mathrm{~mm}$ ID, $0.25 \mu \mathrm{m}$ film thickness, J\&W Scientific, Folsom, CA, USA) was $1 \mathrm{~mL} / \mathrm{min}$. The analysis was performed in the splitless mode, and the injector temperature was $250^{\circ} \mathrm{C}$. The column was held at $40^{\circ} \mathrm{C}$ for $3 \mathrm{~min}$ and then increased from $40^{\circ} \mathrm{C}$ to $220^{\circ} \mathrm{C}$ at a rate of $4^{\circ} \mathrm{C} / \mathrm{min}$, held at $220^{\circ} \mathrm{C}$ for $2 \mathrm{~min}$, and finally increased to $230^{\circ} \mathrm{C}$ at a rate of $8^{\circ} \mathrm{C} / \mathrm{min}$ and held for $3 \mathrm{~min}$.

2.5. Identification of Components. The volatile components were identified by comparing their mass spectra to spectra from MS libraries (NIST 05, WILEY 7.0). The linear retention indices (RI) of the compounds were calculated using a series of $n$-alkanes. Identifications were confirmed by comparing Kovats retention indices (RI) to authentic standards.

\section{Results and Discussion}

3.1. Optimization of Extraction Method. There are many factors that can have a direct impact during the headspacesolid-phase microextraction process. These include the type of fiber, amount of sample, extraction time, extraction temperature, amount of $\mathrm{NaCl}$, and rotor speed.

Choice of SPME Fiber. Five fibers coated with PA, PDMS, $\mathrm{PDMS} / \mathrm{DVB}, \mathrm{CAR} / \mathrm{PDMS}$, and DVB/CAR/PDMS were evaluated for the extraction of the volatile compounds in foxtail millet sake. Among the tested fibers (Figure 1), the area count in 50/30 $\mu \mathrm{m} \mathrm{DVB/CAR/PDMS} \mathrm{fiber} \mathrm{coating} \mathrm{was} \mathrm{significantly}$ higher than others $(p<0.05)$. The extraction of analytes can be attributed to their characteristics associated with the fiber coating. Comparing the coating of two single fibers (PDMS and PA), PA fiber had higher peak areas than the PDMS fiber; PA fiber attracts the polar compounds more strongly than the PDMS fiber. Mixed fibers coating (CAR/PDMS, $\mathrm{PDMS} / \mathrm{DVB}$, and DVB/CAR/PDMS) applied to volatile and nonvolatile low-to-high polarity and showed high adsorption capacity compared to PA fiber. Usually, the CAR/PDMS fiber is selective to low molecular weight volatile compounds, and the PDMS/DVB fiber is selective to high molecular weight volatile compounds, while the DVB/CAR/PDMS fiber presented to be effective for a more diverse range of volatile compounds [24]. DVB/CAR/PDMS fiber was also selected as optimal fiber in cherry wine [25], Chinese liquor [13], and rice wine [4] expressed high efficiency and selectivity in analyzing aroma of alcoholic beverage.

Amount of Sample. Amounts of 2, 4, 6, 8, and $10 \mathrm{~mL}$ were selected to determine how the sample amount affects total peak area. Results showed that total peak areas with sample amount of 8 and $10 \mathrm{~mL}$ were significantly higher than those of 2,4 , and $6 \mathrm{~mL}(p<0.05)$. No significant difference was detected between 8 and $10 \mathrm{~mL}(p>0.05)$, while $8 \mathrm{~mL}$ served as the optimal sample amount. Because the HS-SPME mechanism is based on the equilibrium of analytes among three phases (polymeric coating, headspace, and sample), sample volume directly affects two phases of headspace and sample, which in turn influence extraction efficiency [26, 27]. The amount of analyte removed by the fiber is proportioned to the compound concentration in the sample amount. Along with the increase of sample amount, concentration of volatile compounds increases in headspace. When volatile compounds caused equilibrium concentration of fiber, absorption efficiency had no obvious change. Therefore, different alcoholic beverages have different sample amount; 5, 7, and $8 \mathrm{~mL}$ were the optimal amount in beer [14], rice wine [4], and cherry wine [25] using $15 \mathrm{~mL}$ headspace vial, respectively.

Extraction Time. Extraction time also affects extraction efficiency. The foxtail millet sake samples were extracted for 10 , $20,30,40$, and $50 \mathrm{~min}$, respectively (Figure 1). Results showed that the total peak area was clearly higher at an extraction time in 30,40 , and $50 \mathrm{~min}$. No significant change was found when it was prolonged from 30 to $50 \mathrm{~min}(p<0.05)$. Therefore, $30 \mathrm{~min}$ was chosen as the optimal extraction time. Extraction time is the time required for an analyte to reach equilibrium between the sample matrix and the stationary phase [28], which is one of the most important parameters in HS-SPME process, because it influences the equilibrium of analytes between headspace and fiber coating. Some studies showed that optimal extraction time usually was $30-45 \mathrm{~min}$ in alcoholic beverage [4, 12-14], which was consistent with the finding in millet sake.

Extraction Temperature. Different extracting temperatures $\left(30,40,50,60\right.$, and $\left.70^{\circ} \mathrm{C}\right)$ were evaluated in the HS-SPME parameter screening experiment. The results showed that the quantity of volatile compound reached the highest total peak area while extracting temperature was $50^{\circ} \mathrm{C}$ (Figure 1). However, the extraction efficiencies were significantly low $(p<0.05)$ when the extracting temperature was raised to $70^{\circ} \mathrm{C}$. In general, heat provides energy for analyte molecule to overcome energy barriers tying it to the matrix, thus facilitating release of analytes into the headspace. However, it can adversely affect adsorption of analytes by coating due to the partition coefficients decrease [29]. Consistent results were also found in rice wine [4] and cherry wine [25] with the optimal extraction temperature at $50^{\circ} \mathrm{C}$. However, $70^{\circ} \mathrm{C}$ was selected as optimal extraction temperature of SPME for analysis haloanisole in wine [30]. High extracting temperature could lead to decline of adsorption of the coating and degradation of detected product.

Rotor Speed. The figure shows the efficiency of the extraction in different rotor speed of $0,5,10,15$, and $20 \mathrm{rpm}$. The total peak area increased as rotor speed increased; $10 \mathrm{rpm}$ was the most suitable rotor speed (Figure 1). Agitation accelerates the transfer of analytes from the sample matrix to the coating fiber [29]. However, rotor speed was generally regarded as an important factor in SPME methodology. In studies of volatile compound of rice wine [4], beer [14], liquor Chinese [15], and cherry wine [25], the rotor speed was omitted in the optimization of SPME. In the present study, the rotor speed also showed that it was an important factor in SPME (Figure 1).

Concentration of $\mathrm{NaCl}$. $\mathrm{NaCl}$ levels of $0,0.5,1.0,1.5$, and $2.0 \mathrm{~g}$ were selected for testing of the concentration of $\mathrm{NaCl}$ on the total peak area. The total peak area increased as extraction time increased; $1.5 \mathrm{~g}$ was the most suitable $\mathrm{NaCl}$ 

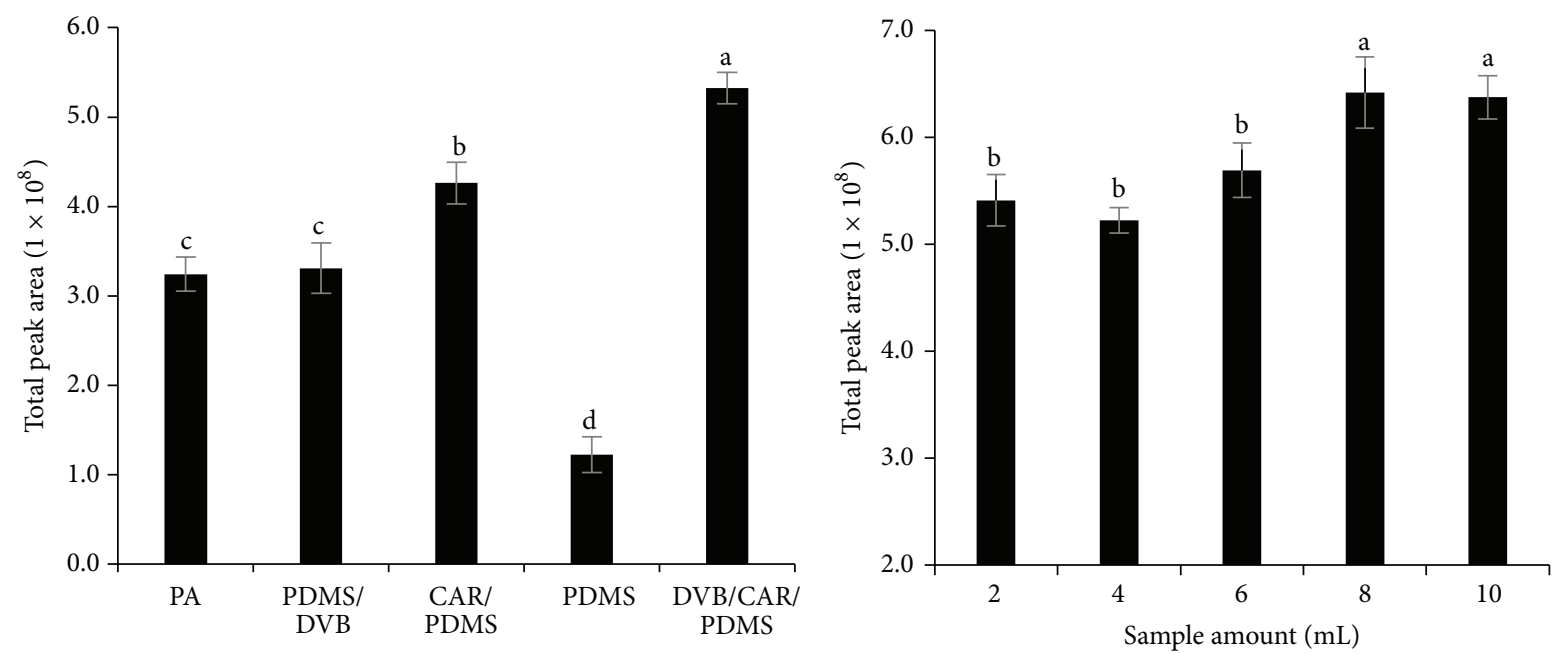

SPME fiber
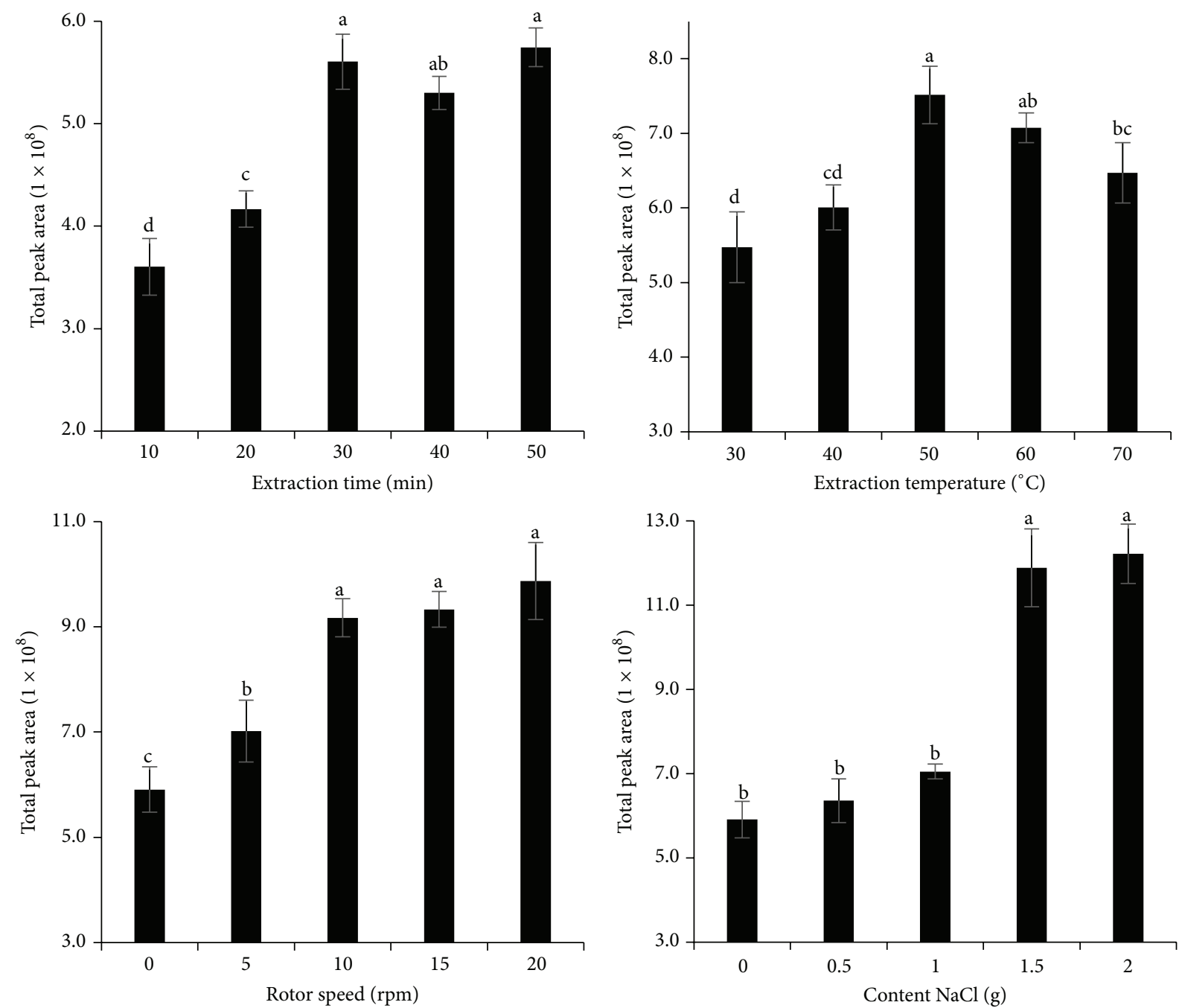

FIGURE 1: Optimization of HS-SPME. Effect of fibers, sample amount, extraction time, extraction temperature, rotor speed, and content NaCl. Bars with different letters have significantly different $(p<0.05)$ mean values. 


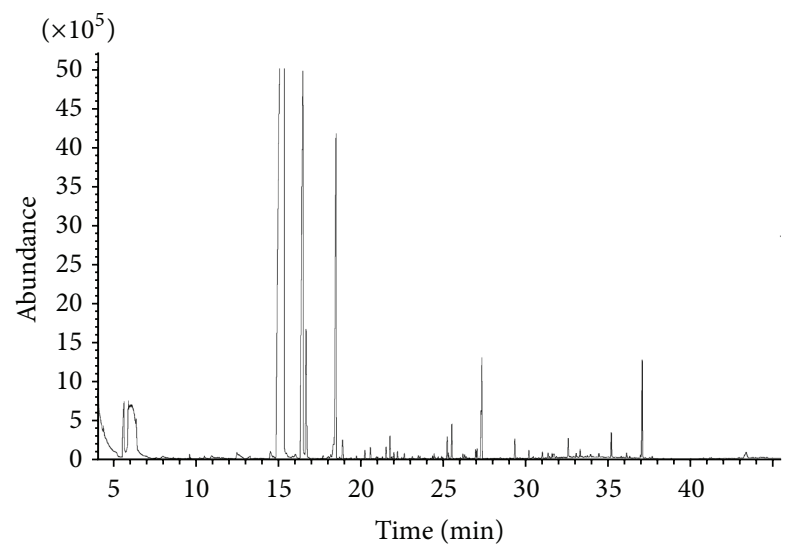

FIGURE 2: Chromatograms of the volatile compounds in foxtail millet sake.

levels (Figure 1). In the SPME procedure, the salting-out effect was used to modify the matrix through the addition of salts such as $\mathrm{NaCl}$ to increase the ionic strength of the water and so decrease the solubility of analytes and increase the release of analytes into the headspace, thereby contributing to enhanced adsorption onto the fiber [29]. Comparing with rice wine [4], beer [14], and cherry wine [25], less $\mathrm{NaCl}$ was added into the sample, which may relate to the property of millet sake.

3.2. Volatile Compounds in Foxtail Millet Sake. Then $8 \mathrm{~mL}$ of sample was placed in a $15 \mathrm{~mL}$ headspace vial with $1.5 \mathrm{~g}$ of $\mathrm{NaCl}$; a 50/30 $\mu \mathrm{m} \mathrm{DVB/CAR/PDMS} \mathrm{SPME} \mathrm{fiber} \mathrm{was} \mathrm{used} \mathrm{for}$ extraction at $50^{\circ} \mathrm{C}$ for $30 \mathrm{~min}$ with $10 \mathrm{rpm}$ continuous stirring.

The total ionic current (TIC) chromatogram of the volatile components in foxtail millet sake was shown in Figure 2. A total of 41 volatile compounds were tentatively identified in Table 2. These compounds included esters (9 compounds), alcohols (6 compounds), acids (4 compounds), aldehydes (4 compounds), hydrocarbons (9 compounds), benzene derivatives ( 7 compounds), and other compounds ( 2 compounds). Their concentrations varied from 8.27 to $7,272.82 \mu \mathrm{g} / \mathrm{L}$. The major volatile components present in sake sample were ethyl acetate, phenylethyl alcohol, butanedioic acid diethyl ester, and hexadecane.

Esters. Esters were the largest group in terms of the number and concentration of aroma compounds identified in sample. Nine esters were detected. The subtotal concentration was $10,993.01 \pm 631.34 \mu \mathrm{g} / \mathrm{L}, 43.52 \pm 1.38 \%$ of the total volatile compounds detected. This volatile fraction was mainly composed of ethyl acetate, octanoic acid methyl ester, and butanedioic acid diethyl ester. All of esters were ethyl esters except for octanoic acid methyl ester. Ethyl esters detected in the sample included monoethyl esters and monodiethyl esters. Monoethyl esters are common in alcoholic beverages. Of the 6 monoethyl esters detected here, hexanoic acid ethyl ester was rated above 1. Its OAV was the highest of any of the odor active compounds in the sample. Hexanoic acid ethyl ester is responsible for the "fruity" and "sweet" sensory properties of wine. Two diethyl esters were detected, but they had low OAV and made little contribution to the aroma of the wine. Methyl esters, such as octanoic acid methyl ester, were also identified. This ester had an OAV above 1, so it played a minor role in the overall aroma profile of wine.

Alcohols. Alcohols showed the second largest concentration of aromatic compounds identified in the sample. The subtotal concentration of alcohols was $8,320.49 \pm 1,087.30 \mu \mathrm{g} / \mathrm{L}$, which made up $32.88 \pm 3.09 \%$ of the total volatile compounds detected. Phenylethyl alcohol was the most abundant alcohol, accounting for $28.71 \pm 3.80 \%$ of the total volatile compounds in sample studied. Among 6 alcohols detected, only 2nonanol had OAV values above 1. It provides the fatty sensory properties of the wine.

Acids and Aldehydes. In the present study, four acids were detected in the wines. The subtotal concentration of acids was $159.53 \pm 15.97 \mu \mathrm{g} / \mathrm{L}$, which made up $0.63 \pm 0.05 \%$ of the total volatile compounds detected. These were citronellol, linalool, and limonene, and their concentrations were very low. These acids detected had OAV values lower than 1, indicating that they play a lesser role in the overall aroma profile of wine. Four aldehydes were detected in sample. The subtotal concentration and the relative subtotal were $127.40 \pm 6.92 \mu \mathrm{g} / \mathrm{L}$ and $0.51 \pm 0.04 \%$, respectively. Benzeneacetaldehyde (sweet, floral), decanal (green, citrus), and dodecanal (fatty, woody) all showed OAVs above 1 , so they played a lesser role in the overall aroma profile of wine.

Hydrocarbons, Benzene Derivatives, and Other Compounds. Nine hydrocarbons, 7 benzene derivatives, and 2 others were identified in sample. The subtotal concentration and the relative subtotal of hydrocarbons, benzene derivatives, and other compounds were $2,995.98 \pm 188.67 \mu \mathrm{g} / \mathrm{L}, 917.06 \pm$ $139.82 \mu \mathrm{g} / \mathrm{L}$, and $124.17 \pm 18.84 \mu \mathrm{g} / \mathrm{L}$ and $11.86 \pm 0.35 \%$, $3.63 \pm 0.56 \%$, and $0.49 \pm 0.09 \%$, respectively. Hydrocarbons and benzene derivatives may have come from foxtail millet. Hydrocarbons showed relatively high flavor thresholds and may have made little contribution to the odor of the wine. OAVs of styrene (floral sweet), 2-methylnaphthalene (phenolic), and 1-methylnaphthalene (phenolic) were 6.96, 6.41, and 3.41. They made important contribution to the odor of the foxtail millet sake. Among other compounds, benzothiazole showed OAVs of no more than 1, providing the gasoline and rubber sensory properties of wine.

\section{Conclusions}

The present study was the first report to describe the volatile chemical composition and odor active compounds of foxtail millet sake performed by HS-SPME-GC-MS and OAV, respectively. Analyses of the volatile constituents in sample indicated ethyl acetate, phenylethyl alcohol, butanedioic acid diethyl ester, and hexadecane to be the predominant components. The OAV results revealed the 10 most odor active compounds with OAV within the range of $1.10-52.32$ to be 


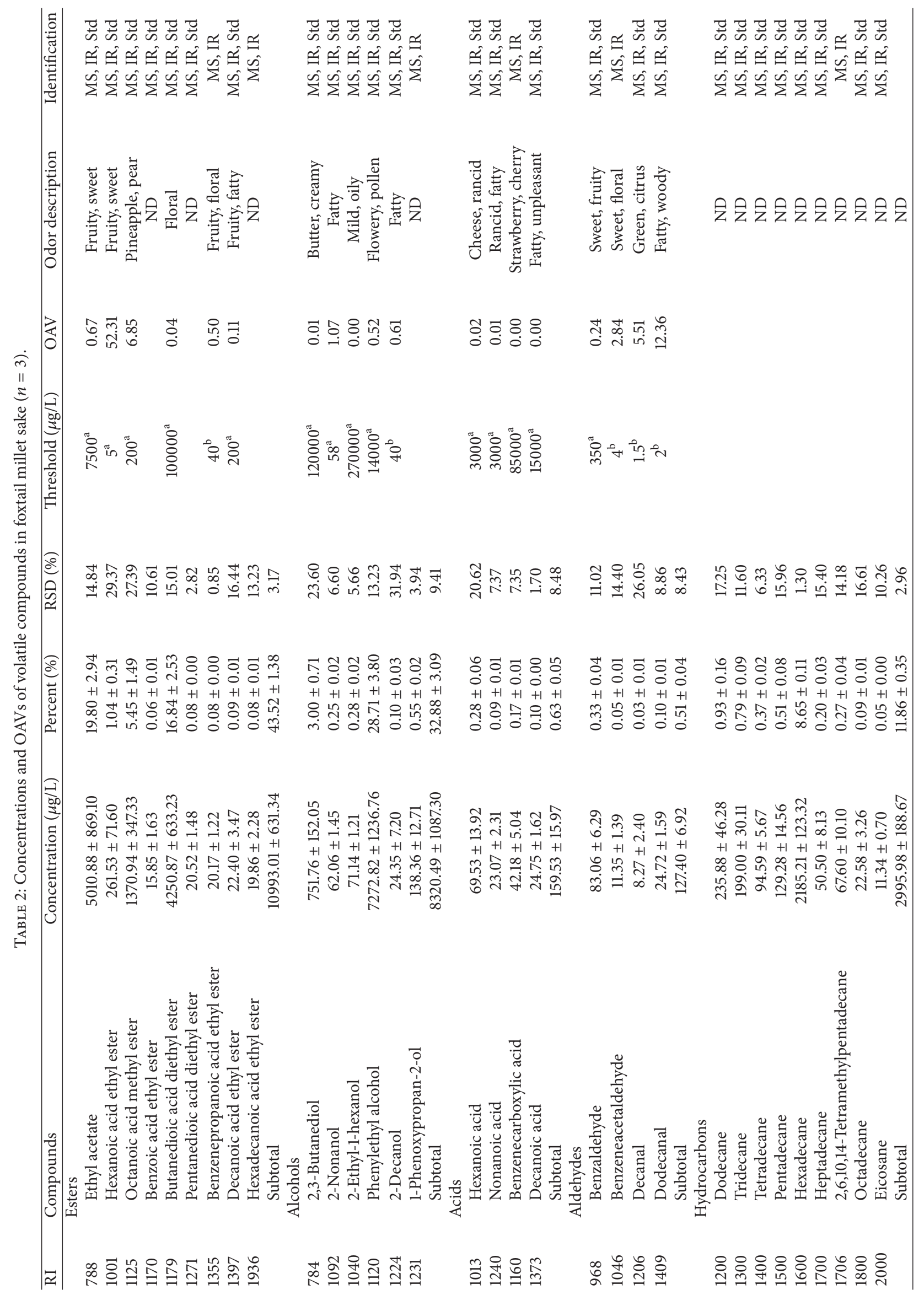




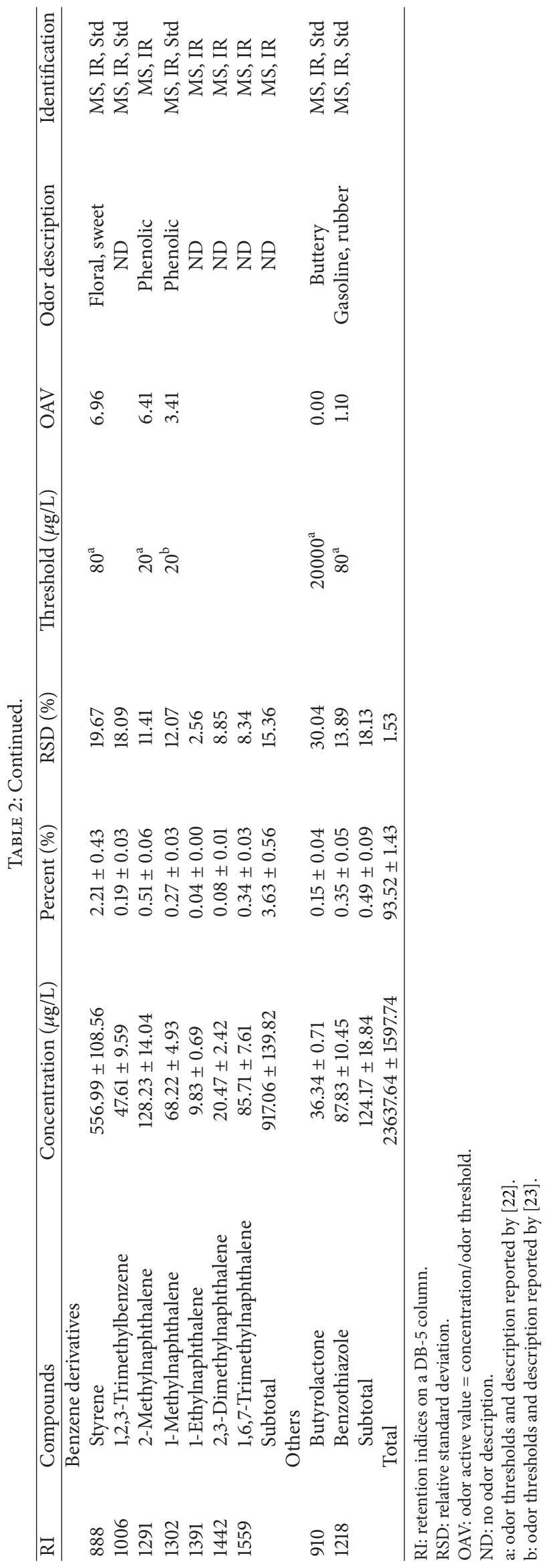


the key odorants in the sample. The results could be used to evaluate the quality of foxtail millet sake.

\section{Conflict of Interests}

The authors declare that there is no conflict of interests regarding the publication of this paper.

\section{Acknowledgment}

This research was supported by the Special Fund for AgroScientific Research in the Public Interest (201303069).

\section{References}

[1] V. D. Pawar and G. M. Machewad, "Processing of foxtail millet for improved nutrient availability," Journal of Food Processing and Preservation, vol. 30, no. 3, pp. 269-279, 2006.

[2] S. H. Liang, G. L. Yang, and Y. X. Ma, "Chemical characteristics and fatty acid profile of foxtail millet bran oil," Journal of the American Oil Chemists' Society, vol. 87, no. 1, pp. 63-67, 2010.

[3] A. Isogai, H. Utsunomiya, R. Kanda, and H. Iwata, "Changes in the aroma compounds of sake during aging," Journal of Agricultural and Food Chemistry, vol. 53, no. 10, pp. 4118-4123, 2005.

[4] T. Luo, W. Fan, and Y. Xu, "Characterization of volatile and semi-volatile compounds in Chinese rice wines by headspace solid phase microextraction followed by gas chromatographymass spectrometry," Journal of the Institute of Brewing, vol. 114, no. 2, pp. 172-179, 2008.

[5] I. Atsuko, U. Hitoshi, and I. Hiroshi, "Changes in the concentrations of sotolon and furfural during the maturation of sake," Journal of the Brewing Society of Japan, vol. 99, no. 5, pp. 374380, 2004.

[6] K. Ito, T. Ohta, and S. Haraj, "Interaction between rice constituents and aroma components in sake, mash, and adsorption of aroma components by steamed rice," Journal of the Brewing Society of Japan, vol. 82, no. 4, pp. 289-293, 1987.

[7] A. Isogai, H. Utsunomiya, and H. Iwataj, "Changes in the concentrations of sotolon and furfural during the maturation of sake," Journal of the Brewing Society of Japan, vol. 99, no. 5, pp. 374-380, 2004.

[8] K. Sakamoto, M. Shimoda, and Y. Osajima, "Concentration in porapak Q column of volatile compounds in sake for analysis," Nippon Nōgeikagaku Kaishi, vol. 67, no. 4, pp. 685-691, 1993.

[9] K. Takahashi, "Studies on volatile carbonyl compounds in sake (part 2)," Journal of the Brewing Society of Japan, vol. 64, no. 10, pp. 907-910, 1969.

[10] Y. Yoshizaki, H. Yamato, K. Takamine, H. Tamaki, K. Ito, and Y. Sameshima, "Analysis of volatile compounds in shochu koji, sake koji, and steamed rice by gas chromatography-mass spectrometry," Journal of the Institute of Brewing, vol. 116, no. 1, pp. 49-55, 2010.

[11] B. Jiang and Z. W. Zhang, "Volatile compounds of young wines from cabernet sauvignon, cabernet gernischet and chardonnay varieties grown in the loess plateau pegion of China," Molecules, vol. 15, no. 12, pp. 9184-9196, 2010.

[12] V. Canuti, M. Conversano, M. L. Calzi, H. Heymann, M. A. Matthews, and S. E. Ebeler, "Headspace solid-phase microextraction-gas chromatography-mass spectrometry for profiling free volatile compounds in Cabernet Sauvignon grapes and wines," Journal of Chromatography A, vol. 1216, no. 15, pp. 3012-3022, 2009.
[13] W. Fan and M. C. Qian, "Headspace solid phase microextraction and gas chromatography-olfactometry dilution analysis of young and aged Chinese 'Yanghe Daqu' liquors," Journal of Agricultural and Food Chemistry, vol. 53, no. 20, pp. 7931-7938, 2005.

[14] O. Pinho, I. M. Ferreira, and L. H. Santos, "Method optimization by solid-phase microextraction in combination with gas chromatography with mass spectrometry for analysis of beer volatile fraction," Journal of Chromatography A, vol. 1121, no. 2, pp. 145$153,2006$.

[15] P. G. Hill and R. M. Smith, "Determination of sulphur compounds in beer using headspace solid-phase microextraction and gas chromatographic analysis with pulsed flame photometric detection," Journal of Chromatography A, vol. 872, no. 1-2, pp. 203-213, 2000.

[16] Y. Xu, W. Fan, and M. C. Qian, "Characterization of aroma compounds in apple cider using solvent-assisted flavor evaporation and headspace solid-phase microextraction," Journal of Agricultural and Food Chemistry, vol. 55, no. 8, pp. 3051-3057, 2007.

[17] R. Eisert and K. Levsen, "Solid-phase microextraction coupled to gas chromatography: a new method for the analysis of organics in water," Journal of Chromatography A, vol. 733, no. 1-2, pp. 143-157, 1996.

[18] H. Kataoka, H. L. Lord, and J. Pawliszyn, "Applications of solidphase microextraction in food analysis," Journal of Chromatography $A$, vol. 880, no. 1-2, pp. 35-62, 2000.

[19] W. Wardencki, M. Michulec, and J. Curyło, "A review of theoretical and practical aspects of solid-phase microextraction in food analysis," International Journal of Food Science \& Technology, vol. 39, no. 7, pp. 703-717, 2004.

[20] M. Vilanova and C. Martínez, "First study of determination of aromatic compounds of red wine from Vitis vinifera cv. Castañal grown in Galicia (NW Spain)," European Food Research and Technology, vol. 224, no. 4, pp. 431-436, 2007.

[21] AOAC, Official Methods of Analysis, Association of Official Analytical Chemists, Washington, DC, USA, 16th edition, 1996.

[22] B. Jiang and Z. Zhang, "Volatile compounds of young wines from cabernet sauvignon, cabernet gernischet and chardonnay varieties grown in the loess plateau region of China," Molecules, vol. 15, no. 12, pp. 9184-9196, 2010.

[23] G. A. Burdock, Fenaroli's Handbook of Flavor Ingredients, Taylor \& Francis Group, London, UK, 6th edition, 2009.

[24] N. Li, F. Zheng, M. Liang, and B. Sun, "Identification of volatile flavor compounds in Chinese Sinkiang camel-naizi using different solid phase microextraction fibers," Food Science and Biotechnology, vol. 19, no. 4, pp. 993-998, 2010.

[25] Z. Xiao, X. Zhou, Y. Niu, D. Yu, J. Zhu, and G. Zhu, “Optimization and application of headspace-solid-phase micro-extraction coupled with gas chromatography-mass spectrometry for the determination of volatile compounds in cherry wines," Journal of Chromatography B, vol. 978-979, pp. 122-130, 2015.

[26] C. E. D. L. da Silva, W. F. da Costa, S. Minguzzi, R. C. D. L. da Silva, and E. Simionatto, "Assessment of volatile chemical composition of the essential oil of Jatropha ribifolia (Pohl) baill by HS-SPME-GC-MS using different fibers," Journal of Analytical Methods in Chemistry, vol. 2013, Article ID 352606, 8 pages, 2013.

[27] G. Vas and K. Vékey, "Solid-phase microextraction: a powerful sample preparation tool prior to mass spectrometric analysis," Journal of Mass Spectrometry, vol. 39, no. 3, pp. 233-254, 2004.

[28] Y. Liu, Z. Miao, W. Guan, and B. Sun, "Analysis of organic volatile flavor compounds in fermented stinky tofu using SPME 
with different fiber coatings," Molecules, vol. 17, no. 4, pp. 37083722, 2012.

[29] J. S. Câmara, M. Arminda Alves, and J. C. Marques, "Development of headspace solid-phase microextraction-gas chromatography-mass spectrometry methodology for analysis of terpenoids in Madeira wines," Analytica Chimica Acta, vol. 555, no. 2, pp. 191-200, 2006.

[30] H. H. Jeleń, M. Dziadas, and M. Majcher, "Different headspace solid phase microextraction-gas chromatography/mass spectrometry approaches to haloanisoles analysis in wine," Journal of Chromatography A, vol. 1313, pp. 185-193, 2013. 

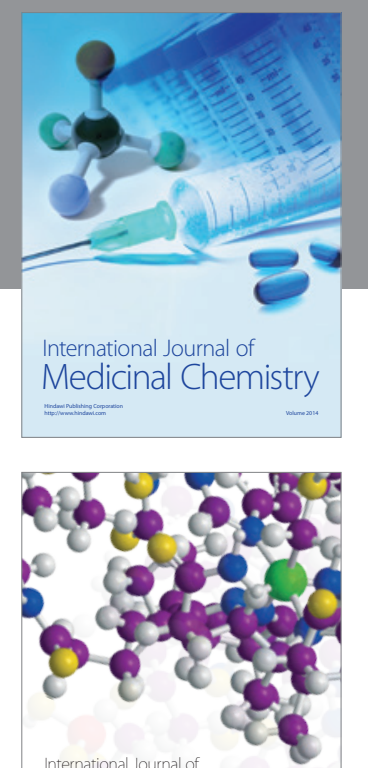

\section{Carbohydrate} Chemistry

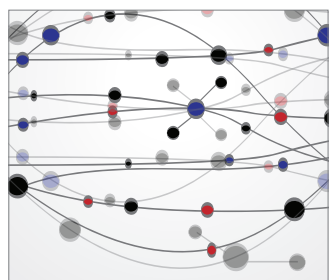

The Scientific World Journal
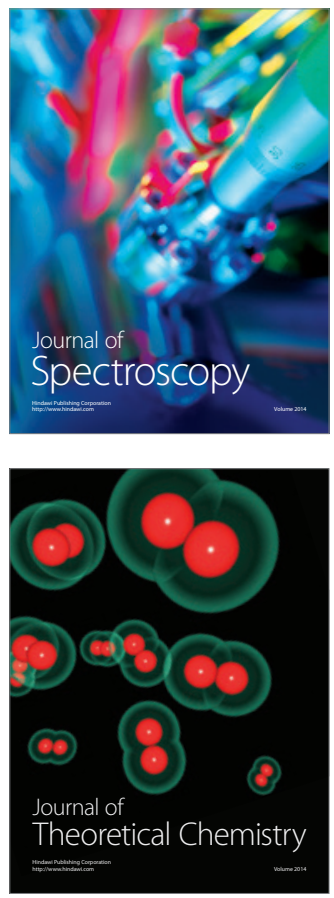
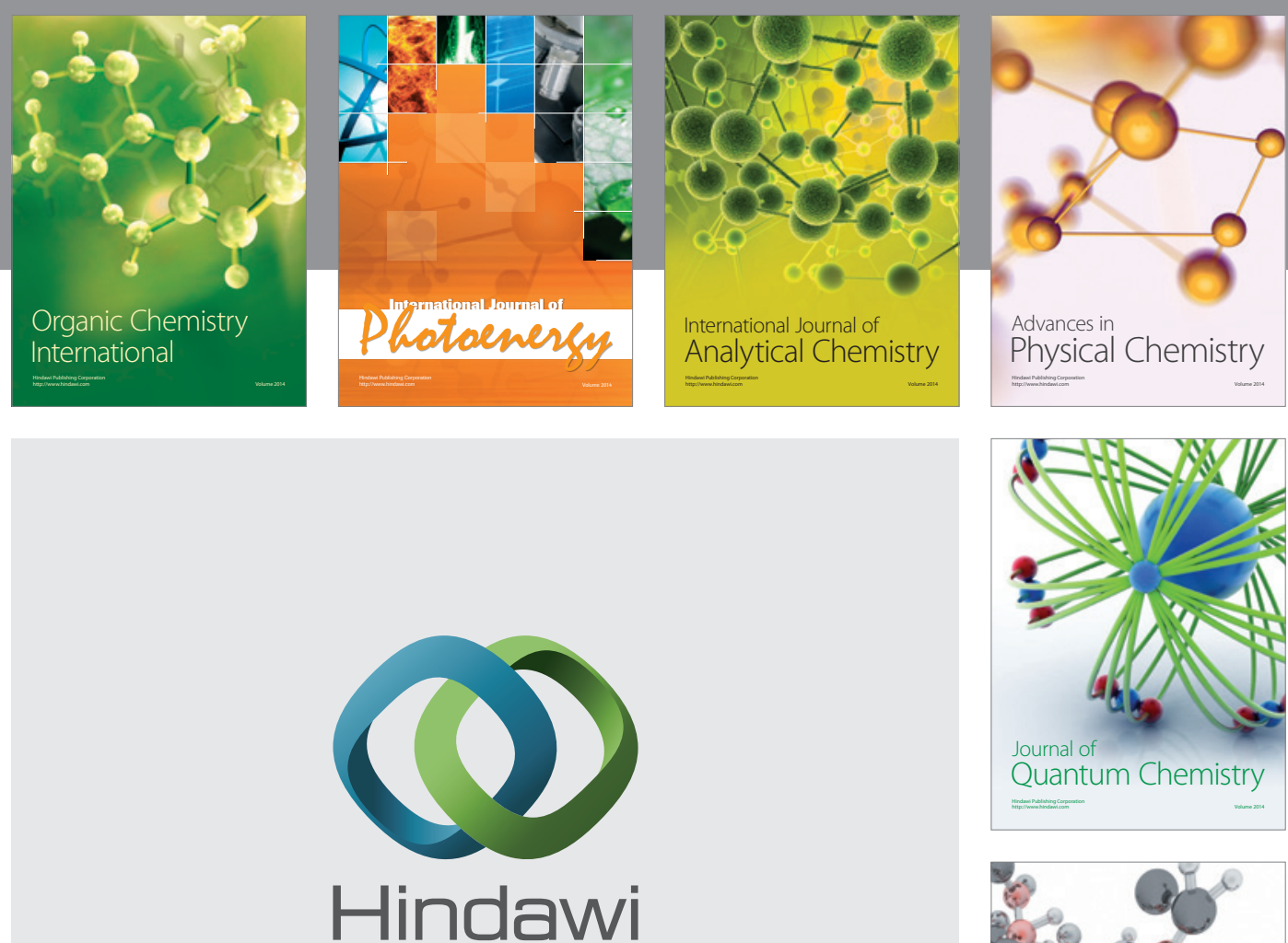

Submit your manuscripts at

http://www.hindawi.com

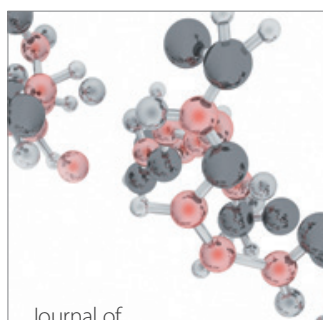

Analytical Methods

in Chemistry

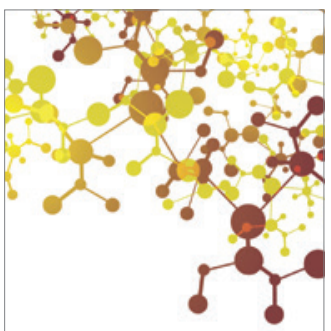

Journal of

Applied Chemistry

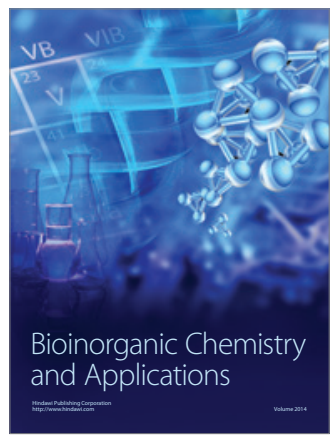

Inorganic Chemistry
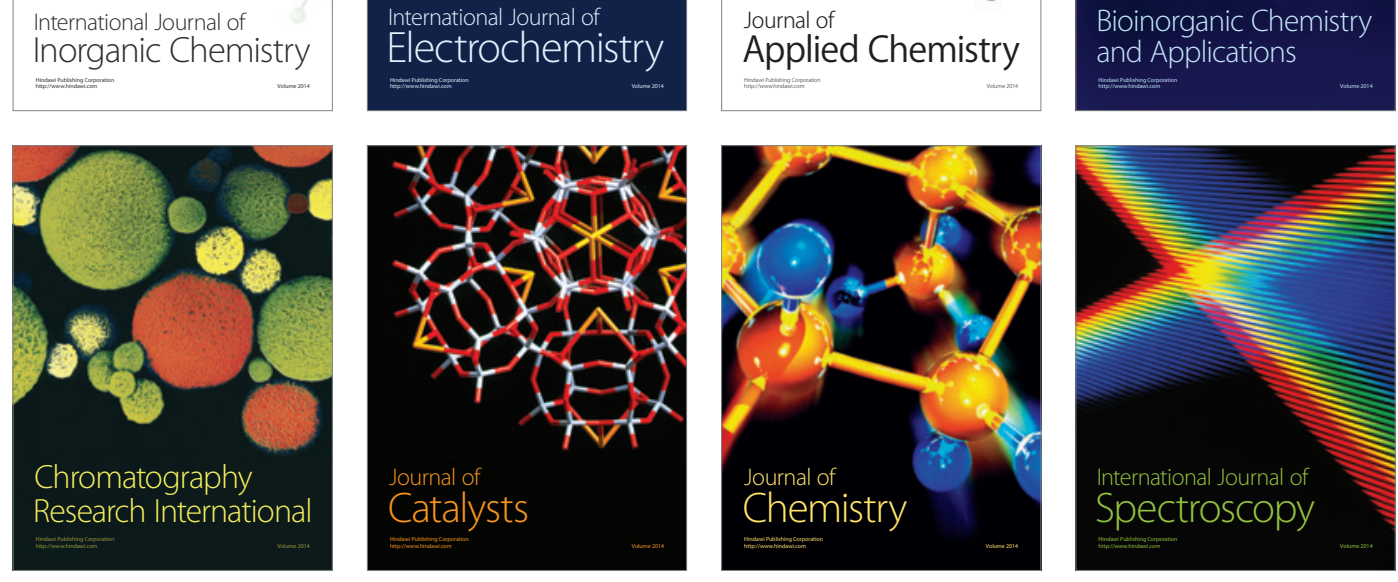